\title{
Paradigm Shifts in Perspective III: The Discovery of Tumor Necrosis Factor
}

\author{
Jonathan D. Kaunitz
}

Received: 14 January 2014 / Accepted: 16 January 2014/Published online: 21 February 2014

(C) Springer Science+Business Media New York (Outside the USA) 2014

\section{Genius is $1 \%$ inspiration and $99 \%$ perspiration}

(Quotation attributed to Thomas A. Edison).

With this third installment of the "Paradigm Shifts in Perspective" series, I have chosen to highlight a discovery of immense impact—not only on the field of gastroenterology, but also of enormous importance to the therapy of chronic inflammatory conditions and also to tumor immunologynamely, the discovery of tumor necrosis factor (TNF), as first reported by Carswell et al. in 1975 [1]. As described in her recent memoir [2], Mrs. Carswell-Richards was working in the Memorial Sloan-Kettering Cancer Center in New York in the laboratory of Lloyd J. Old (Fig. 1) on a project in which they sought to discover a serum factor which necrosed tumors in response to an antigenic challenge with endotoxin, as bacterial lipopolysaccharide (LPS) was then termed:

...Gross virus caused spontaneous leukemia in adult mice of the AKR strain...We observed that injecting serum from mice of other strains caused regression of the AKR disease, at least temporarily.... Rapidly growing Meth A tumors never responded to any anticancer treatments with the exception of endotoxin, which caused tumor hemorrhagic necrosis but severe toxicity. When day 7 arrived, the mice were injected with the "toxic" serum, then put to bed for the night.

\section{J. D. Kaunitz ( $\bowtie)$}

Medical Service, Greater Los Angeles VA Healthcare SystemUCLA School of Medicine, Los Angeles, CA 90073, USA e-mail: jake@ucla.edu

J. D. Kaunitz

Departments of Medicine and Surgery, UCLA School of Medicine, Los Angeles, CA 90073, USA
On the following day, the day that TNF was discovered, the mice were alive and well, but their round, fleshy tumors of the previous day were flat and black! There was nothing remaining except a black scab where the tumor had been. Lloyd Old was summoned to the animal room to see this apparent miracle, and he was amazed. What had caused this? Thus, began 4 years of inquiry into proving or disproving that the phenomenon was caused by residual endotoxin, interferon, a combination of the two, or possibly something else. The answers did not come easily or quickly, and Lloyd Old never published unless he was totally convinced that the results were correct. He never wanted to be in a situation where his publication had to be retracted.

... An interferon-free fraction causing tumor necrosis still killed L cells but not normal cells, and endotoxin was absent ... Finally, it was clear that neither residual endotoxin nor interferon were the cause of tumor necrosis in vivo and $\mathrm{L}$ cell cytotoxicity in vitro. The discovery paper was published in the Proceedings of the National Academy of Sciences in September 1975; the name given to this previously unidentified protein, tumor necrosis factor (TNF), was chosen because of its amazing tumor-damaging capability.

During the latter 1970s, murine TNF serum was produced in large quantities, substantially purified by multi-step chromatography, studied in vivo and in vitro in our lab, and shared with other investigators...

It became evident that TNF played a major role in inflammation and immunity, but genetic sequencing 


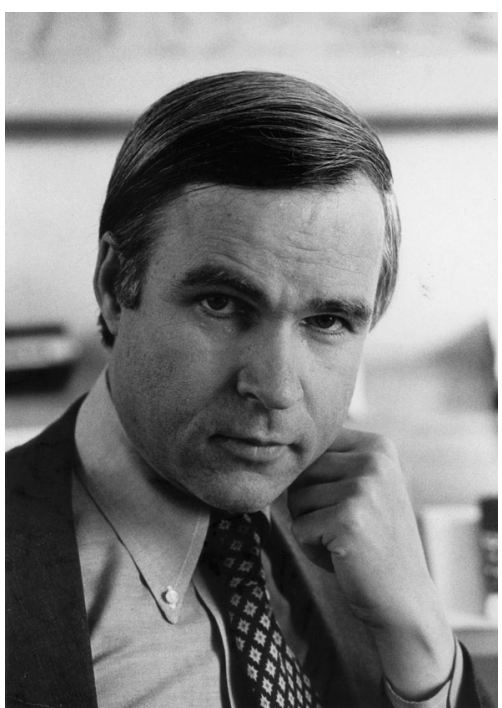

Fig. 1 Dr. Lloyd J. Old, approx. 1974 (photo courtesy of the Cancer Research Institute)

of ...TNF ... was the crucial step toward greater understanding of this amazing molecule. Today, TNF research is in the hands of investigators around the world, but its discovery was due to a brilliant scientist and treasured friend, Lloyd J. Old. (Adapted from [1], with permission from the author.)

Although there is much "perspiration" involved in the discovery of TNF, from Dr. Coley's painstaking injection of patients with bacteria and toxins in an attempt to recreate the phenomenon of spontaneous tumor regression following febrile bacterial infections, to Murray Shear's meticulous isolation, purification, and biological testing of LPS, to Miss Carswell's collection and purification of serum from LPS-injected mice described above, the paradigm shift that occurred with the discovery of TNF was that a protein secreted from a population of circulating cells could have powerful and systemic effects, giving birth to the field of cytokines, spawning an estimated 180,000 publications since its first description [3]. Perhaps not coincidentally, and somewhat ironically, Dr. Coley's patient Elizabeth Dashiell is implicated in the early funding of cancer research by the Rockefellers, eventuating in the creation of the Sloan-Kettering Memorial Cancer Center, where TNF was discovered [4]. Although the use of TNF in cancer immunotherapy has been mostly disappointing [5], anti-TNF "biologic" drugs have had powerful impact on the therapy of inflammatory bowel disease, demonstrating yet again that major therapeutic shifts can be decades or even centuries in the making and that they might arise from scientific disciplines entirely remote from their intended application.

Dr. Chadee and I have compiled a timeline of the major achievements in the field of TNF research, demonstrating the slow accumulation of knowledge leading up to the "pivot point" of the discovery of TNF to the explosion of data, culminating in the approval of the TNF neutralizing antibody infliximab by the U.S. Food and Drug Administration in 1999, 24 years after the discovery of TNF, demonstrating yet again the striking and rapid changes that occur after a paradigm shift.

Acknowledgments The author thanks Michelle Liew of the Cancer Research Institute for her helpful advice and assistance.

\section{References}

1. Carswell EA, Old LJ, Kassel RL, Green S, Fiore N, Williamson B. An endotoxin-induced serum factor that causes necrosis of tumors. Proc Natl Acad Sci USA. 1975;72:3666-3670.

2. Carswell-Richards EA, Williamson BA. A man of vision and the discovery of tumor necrosis factor. Cancer Immun. 2012;12:1-3.

3. Aggarwal BB, Gupta SC, Kim JH. Historical perspectives on tumor necrosis factor and its superfamily: 25 years later, a golden journey. Blood. 2012;119:651-665.

4. Hall SS. A Commotion in the Blood: Life, Death, and the Immune System. New York: Henry Holt; 1997.

5. Starnes CO. Coley's toxins in perspective. Nature. 1992;357:11-12. 